\title{
Food Intake and Functional Constipation: A Cross-Sectional Study of 3,835 Japanese Women Aged 18-20 Years
}

\author{
Kentaro MURAKAmI $^{1}$, Satoshi SASAKI ${ }^{1, *}$, Hitomi OKUBO ${ }^{2}$, Yoshiko TAKAHASHI ${ }^{1}$, Yoko Hosoi ${ }^{1}$, \\ Mami ITABASHI ${ }^{1}$ and the Freshmen in Dietetic Courses Study II Group \\ ${ }^{1}$ Nutritional Epidemiology Program, National Institute of Health and Nutrition, Tokyo 162-8636, Japan \\ ${ }^{2}$ Department of Nutrition Sciences, Kagawa Nutrition University, Saitama 350-0288, Japan
}

(Received July 14, 2006)

\begin{abstract}
Summary Although we previously observed significant associations between intakes of several foods and constipation, definition of constipation was completely based on subjective perception assessed by a quite simple and single question: do you often have constipation? In this study, we examined the associations between food intake and functional constipation as defined according to symptom-based criteria (Rome I criteria: straining, hard stools, incomplete evacuation, and infrequency of bowel movement). Subjects were 3,835 female Japanese dietetic students aged 18-20 y from 53 institutions in Japan. Dietary intake was estimated with a validated, self-administered diet history questionnaire. The prevalence of functional constipation was $26.2 \%$. Dietary intakes of several foods were significantly associated with functional constipation. A multivariate adjusted odds ratio $(95 \%$ confidence interval; $p$ for trend) for women in the highest quintile of dietary intake compared with those in the lowest was $0.59(0.46-0.75 ;<0.0001)$ for rice, $0.77(0.61-0.97 ; 0.003)$ for pulses, $1.64(1.30-2.08 ;<0.0001)$ for confectioneries, and $1.41(1.11-1.78 ; 0.01)$ for bread. In conclusion, intake of rice and pulse was negatively and that of confectioneries and bread was positively associated with functional constipation among a population of young Japanese women, which was generally consistent with our previous study where constipation was assessed by a quite simple question.
\end{abstract}

Key Words dietary fiber, food, rice, functional constipation, epidemiology

Constipation is a common health problem (1-4), and food intake is considered to be a major modifiable lifestyle factors associated with this condition $(5,6)$. Foods related to constipation in previous observational studies include dairy products (7), beans (7), meats (7), fruits (7), vegetables $(7)$, rice $(3,8,9)$, eggs $(9)$, confectioneries $(8)$, and several nonalcoholic beverages $(3,7,8,10$, 11). However, while most previous studies have defined constipation according to the infrequency of bowel movement only (10-13) or the subjective perception of patients $(7,8)$, a consensus definition of constipation consists of straining, hard stools, and incomplete evacuation in addition to infrequency (Rome criteria) (14). Further, although Wong et al. (3) and Nakaji et al. (9) defined constipation using the Rome criteria and original subjective criteria, respectively, they assessed diet with a non-validated, relatively simple food frequency questionnaire. Moreover, although we previously observed associations between intakes of several foods and constipation (11), using a previously validated, self-administered, diet history questionnaire (DHQ) (15-17), the definition of constipation was completely based on subjective perception assessed by a quite simple and single question: do you often have constipation?

*To whom correspondence should be addressed.

E-mail: stssasak@nih.go.jp
Thus, to our knowledge, no study has so far investigated the relationship of food intake, as assessed with a validated assessment method, to functional constipation, as defined using symptom-based criteria. Here, we examined the associations between food intake, estimated using DHQ, and functional constipation as defined according to the Rome criteria (14).

\section{SUBJECTS AND METHODS}

Subjects and survey procedure. The present study was based on a self-administered questionnaire survey among dietetic students $(n=4,679)$ from 54 institutions in Japan. Staff at each institution distributed a dietary assessment questionnaire (i.e., DHQ) and another questionnaire on other lifestyle items during the preceding month to students during an orientation session or a first lecture designed for freshman students entering dietetic courses in April 2005; in most institutions, this was carried out within 2 wk after the course began to minimize the influence of new school year life on the answers. Students filled out the questionnaires during the session, lecture, or at home and then submitted the completed forms to staff at each institution. Questionnaires used in the present study included the explanation on how to answer questions. To standardize the survey procedure, when students asked how to answer questionnaires, staff at each institution did not 
provide any advice and only asked students to read the explanation on questionnaires carefully. In addition to the two questionnaires for the preceding month, a third questionnaire on lifestyle during the previous $6 \mathrm{y}$ (i.e., junior high school and high school) was also distributed and answered in a similar fashion; in most institutions, this was carried out within 4 wk after the course began because it was considered burdensome for subjects to answer all three questionnaires at the same time and it was considered unlikely that new school year life would influence the answers for lifestyle during the previous $6 \mathrm{y}$.

The staff at each institution checked the responses according to the survey protocol. When missing answers or logical errors were identified, the student was asked to complete the questionnaire again. The staff at each institution mailed the questionnaires to the survey center. Staff at the survey center checked the answers again, and when necessary returned problematic questionnaires to staff at the respective institution, and the student was asked to complete the questionnaires again. All questionnaires were thus checked at least once by staff at each institution and by staff at the survey center. Most surveys were completed by May 2005. The protocol of the present study was approved by the Ethics Committee of the National Institute of Health and Nutrition.

In total, 4,286 students (4,066 women and 220 men) answered all three questionnaires (91.6\%). For the current analysis, we selected female subjects aged $18-20 \mathrm{y}(n=3,967)$ because of the small number of male subjects and women aged $>20 \mathrm{y}$. We then excluded women who were in an institution where the survey had been conducted at the end of May $(n=97)$ because the answers were likely influenced by the new school year life. We further excluded those with extremely low or high energy intake $(<500 \mathrm{kcal} / \mathrm{d}$ or $>4,000 \mathrm{kcal} / \mathrm{d})(n=23)$ because their estimated dietary intake was likely unreliable. We finally excluded those with missing information on the variables used $(n=24)$ for the purpose of multivariate analyses. As some subjects were in more than one exclusion category, the final analysis sample comprised 3,825 women. Although intentional dietary change or use of oral laxatives might have influence on dietary intake or constipation, further exclusion of subjects with intentional dietary change within the preceding year $(n=649)$, those habitually using oral laxatives $(n=231)$, or both did not materially alter the findings, and these subjects were therefore included in the analyses.

Dietary intake. Dietary habits during the previous month were assessed using a previously validated, selfadministered DHQ (15-17). This is a 16-page structured questionnaire that consists of the following seven sections: general dietary behavior; major cooking methods; consumption frequency and amount of six alcoholic beverages; consumption frequency and semiquantitative portion size of 121 selected food and nonalcoholic beverage items; dietary supplements; consumption frequency and semi-quantitative portion size of 19 staple foods (rice, bread, and noodles) and miso (fermented soybean paste) soup; and open-ended items for foods consumed regularly ( $\geq$ once/wk) but not appearing in the DHQ. The food and beverage items and portion sizes in the DHQ were derived primarily from data in the National Nutrition Survey of Japan (18) and several recipe books for Japanese dishes (15).

Estimates of dietary intake for 147 food and beverage items and energy were calculated using an ad hoc computer algorithm for the DHQ, which was based on the Standard Tables of Food Composition in Japan (19). Information on dietary supplements and data from the open-ended questionnaire items were not used in the calculation of dietary intake. The food and nonalcoholic beverage items were grouped into the 18 food groups (as shown in Table 2). Detailed descriptions of the methods used for calculating dietary intake and the validity of the DHQ have been published elsewhere (15-17). The Pearson correlation coefficient (20) between DHQ and 3-d estimated dietary records was 0.48 for energy among 47 women (15). In addition, the mean value of the Spearman correlation coefficients (20) for energyadjusted intakes $(\mathrm{g} / 1,000 \mathrm{kcal})$ of 16 food groups was 0.35 (range: 0.05-0.59) among 92 women (Sasaki S, unpublished observations, 2004).

Constipation. A constipation questionnaire was developed based on a previous study (2) and incorporated into the 20-page questionnaire for lifestyle during the previous $6 \mathrm{y}$. We used the definition of functional constipation recommended by an international workshop on the management of constipation (Rome I criteria) (14). Although the Rome I criteria were modified in 1999 (Rome II criteria) (21), epidemiologic studies have consistently shown that the latter may be too restrictive for the diagnosis of constipation $(2,4)$; we therefore used the former. The Rome I criteria are a consensus definition of constipation consisting of various symptoms including bowel movement frequency (as shown below) (14), and have become the research standard for the definition of constipation (1). The following four questions were used to assess Rome I-defined functional constipation: 1) Do you strain during a bowel movement?; 2) Do you feel an incomplete emptying sensation after a bowel movement?; 3) How often are your stools hard?; and 4) How many bowel movements do you usually have each week? These questions referred to the last 12 mo. For questions 1-3, four answers were offered: never, sometimes ( $<25 \%$ of the time), often ( $\geq 25 \%$ of the time), and always. Functional constipation was defined as meeting two or more of the four criteria [an answer of often or always to questions 1-3 and $<3$ bowel movements per week (question 4)].

Confounding factors. In epidemiologic research, it is usual to divide the main dependent variables (food intake in the present study) and confounding factors (other lifestyle factors described below in the present study) based on previous studies (1-13). Thus, we assessed not only dietary intake but also several lifestyle factors described below in the present survey. In the questionnaires, subjects reported body weight and 
Table 1. Characteristics of subjects. ${ }^{\mathrm{a}}$

\begin{tabular}{|c|c|c|c|c|}
\hline Variable & $\begin{array}{c}\text { All } \\
(n=3,825)\end{array}$ & $\begin{array}{l}\text { Subjects with } \\
\text { functional constipation }^{\mathrm{b}} \\
\quad(n=1,002)\end{array}$ & $\begin{array}{c}\text { Subjects without } \\
\text { functional constipation } \\
\qquad(n=2,823)\end{array}$ & $p^{c}$ \\
\hline Body mass index $\left(\mathrm{kg} / \mathrm{m}^{2}\right)$ & $21.0 \pm 2.8$ & $20.8 \pm 2.5$ & $21.0 \pm 2.9$ & 0.08 \\
\hline$<18.5$ & $557(14.6)$ & $139(13.9)$ & $418(14.8)$ & 0.19 \\
\hline $18.5-24.9$ & $2,976(77.8)$ & $798(79.6)$ & $2,178(77.2)$ & \\
\hline$\geqq 25$ & $292(7.6)$ & $65(6.5)$ & $227(8.0)$ & \\
\hline \multicolumn{5}{|l|}{ Residential block } \\
\hline Hokkaido and Tohoku & $375(9.8)$ & $93(9.3)$ & $282(10.0)$ & 0.20 \\
\hline Kanto & $1,310(34.3)$ & $351(35.0)$ & $959(34.0)$ & \\
\hline Hokuriku and Tokai & $537(14.0)$ & $159(15.9)$ & $378(13.4)$ & \\
\hline Kinki & $765(20.0)$ & $203(20.3)$ & $562(19.9)$ & \\
\hline Chugoku and Shikoku & $421(11.0)$ & $99(9.9)$ & $322(11.4)$ & \\
\hline Kyushu & $417(10.9)$ & $97(9.7)$ & $320(11.3)$ & \\
\hline \multicolumn{5}{|l|}{ Size of residential area } \\
\hline City with a population $\geqq 1$ million & $745(19.5)$ & $195(19.5)$ & $550(19.5)$ & 0.98 \\
\hline City with a population $<1$ million & $2,495(65.2)$ & $652(65.1)$ & $1,843(65.3)$ & \\
\hline Town and village & $585(15.3)$ & $155(15.5)$ & $430(15.2)$ & \\
\hline \multicolumn{5}{|l|}{ Current smoking } \\
\hline No & $3,769(98.5)$ & $980(97.8)$ & $2,789(98.8)$ & 0.02 \\
\hline Yes & $56(1.5)$ & $22(2.2)$ & $34(1.2)$ & \\
\hline \multicolumn{5}{|l|}{ Current alcohol drinking } \\
\hline No & $3,097(81.0)$ & $770(76.9)$ & $2,327(82.4)$ & 0.0001 \\
\hline Yes & $728(19.0)$ & $232(23.2)$ & $496(17.6)$ & \\
\hline \multicolumn{5}{|l|}{ Oral medication usage } \\
\hline No & $3,447(90.1)$ & $840(83.8)$ & $2,607(92.4)$ & $<0.0001$ \\
\hline Yes & $378(9.9)$ & $62(16.2)$ & $216(7.7)$ & \\
\hline Physical activity level & $1.45 \pm 0.15$ & $1.45 \pm 0.16$ & $1.45 \pm 0.15$ & 0.56 \\
\hline Quintile $1(<1.36)$ & $758(19.8)$ & $200(20.0)$ & $558(19.8)$ & 0.96 \\
\hline Quintile $2(1.36-1.38)$ & $772(20.2)$ & $205(20.5)$ & $567(20.1)$ & \\
\hline Quintile $3(1.39-1.42)$ & $765(20.0)$ & $206(20.6)$ & $559(19.8)$ & \\
\hline Quintile 4 (1.43-1.49) & $765(20.0)$ & $196(19.6)$ & $569(20.2)$ & \\
\hline Quintile $5(>1.49)$ & $765(20.0)$ & $195(19.5)$ & $570(20.2)$ & \\
\hline Energy intake (kcal/d) & $1,819 \pm 502$ & $1,835 \pm 531$ & $1,814 \pm 491$ & 0.26 \\
\hline Quintile $1(<1,407)$ & $765(20.0)$ & $206(20.6)$ & $559(19.8)$ & 0.19 \\
\hline Quintile $2(1,407-1,636)$ & $765(20.0)$ & $195(19.5)$ & $570(20.2)$ & \\
\hline Quintile $3(1,637-1,869)$ & $765(20.0)$ & $191(19.1)$ & $574(20.3)$ & \\
\hline Quintile $4(1,870-2,181)$ & $765(20.0)$ & $186(18.6)$ & $579(20.5)$ & \\
\hline Quintile $5(>2,182)$ & $765(20.0)$ & $224(22.4)$ & $541(19.2)$ & \\
\hline
\end{tabular}

${ }^{a}$ Values are mean \pm standard deviation or $n(\%)$.

${ }^{\mathrm{b}}$ Defined according to the Rome I criteria (14).

${ }^{c}$ For continuous variables, independent $t$-test was used; for categorical variables, chi-square test was used.

height, residential area, current smoking (yes or no), and oral medication usage (yes or no). Body mass index (BMI) was calculated as weight $(\mathrm{kg})$ divided by the square of height $(\mathrm{m})$. We classified BMI into three categories $\left(<18.5,18.5-24.9\right.$, and $\left.\geq 25 \mathrm{~kg} / \mathrm{m}^{2}\right)$ according to the Japan Society for the Study of Obesity (22). The reported residential areas were grouped into six categories (Hokkaido and Tohoku; Kanto; Hokuriku and Tokai; Kinki; Chugoku and Shikoku; and Kyushu) based on the regional blocks used in the National Nutrition Survey in Japan (23) (hereafter referred to as 'residential block'). The residential areas were also grouped into three categories according to population size (city with population $\geq 1$ million; city with population $<1$ million; and town and village) (hereafter referred to as 'size of residential area').
Additionally, subjects reported the time when they usually went to bed and arose in the morning, which was used to calculate sleeping hours, and the frequency and duration of high- and moderate-intensity activities, walking, and sedentary activities. Each activity was assigned a metabolic equivalent (MET) value $(24,25)$. The number of hours spent per day on each activity was multiplied by the MET value of that activity, and all MET-hour products were summed to give a total METhour score for the day. Physical activity level was then calculated by dividing total MET-hour score (kcal/kg of body weight/d) by the standard value of basal metabolic rate for Japanese women aged $18-29 \mathrm{y}(23.6 \mathrm{kcal} / \mathrm{kg}$ of body weight/d) (26).

Statistical analysis. Associations between functional constipation (the dependent variable) and energy- 
Table 2. Multivariate adjusted odds ratios (ORs) and 95\% confidence intervals (CIs) for functional constipation ${ }^{\mathrm{a}}$ by quintiles of food intake ${ }^{\mathrm{b}}(n=3,825)$.

\begin{tabular}{|c|c|c|c|c|c|c|}
\hline & \multicolumn{5}{|c|}{ Quintile category of food intake } & \multirow{2}{*}{$-p$ for trend } \\
\hline & 1 & 2 & 3 & 4 & 5 & \\
\hline $\operatorname{Rice}(\mathrm{g} / 1,000 \mathrm{kcal})^{\mathrm{c}}$ & $78[0-101]$ & 119 [101-135] & $152[135-169]$ & $188[169-214]$ & $251[214-448]$ & \\
\hline$n$ with/without functional constipation & $247 / 518$ & $206 / 559$ & $191 / 574$ & $197 / 568$ & $161 / 604$ & \\
\hline Multivariate adjusted OR $(95 \% \text { CI })^{\mathrm{d}}$ & 1.00 & $0.81(0.65-1.02)$ & $0.73(0.58-0.92)$ & $0.76(0.60-0.96)$ & $0.59(0.46-0.75)$ & $<0.0001$ \\
\hline $\operatorname{Bread}(\mathrm{g} / 1,000 \mathrm{kcal})^{\mathrm{c}}$ & $4[0-9]$ & $14[9-18]$ & $23[18-28]$ & $34[28-41]$ & $53[41-171]$ & \\
\hline$n$ with/without functional constipation & $178 / 587$ & $199 / 566$ & $206 / 559$ & $195 / 570$ & $224 / 541$ & \\
\hline Multivariate adjusted OR $(95 \% \mathrm{CI})^{\mathrm{d}}$ & 1.00 & $1.16(0.92-1.47)$ & $1.27(1.00-1.61)$ & $1.17(0.92-1.49)$ & $1.41(1.11-1.78)$ & 0.01 \\
\hline Noodles $(\mathrm{g} / 1,000 \mathrm{kcal})^{\mathrm{c}}$ & $0[0-11]$ & $16[11-24]$ & $31[24-38]$ & $47[38-59]$ & $79[59-355]$ & \\
\hline$n$ with/without functional constipation & $204 / 561$ & $211 / 554$ & $207 / 558$ & $185 / 580$ & $195 / 570$ & \\
\hline Multivariate adjusted OR $(95 \% \mathrm{CI})^{\mathrm{d}}$ & 1.00 & $1.06(0.84-1.33)$ & $1.02(0.81-1.29)$ & $0.90(0.71-1.14)$ & $0.94(0.75-1.19)$ & 0.30 \\
\hline Potatoes $(\mathrm{g} / 1,000 \mathrm{kcal})^{\mathrm{c}}$ & $6[0-8]$ & $10[8-11]$ & 13 [11-15] & 18 [15-22] & 29 [22-165] & \\
\hline$n$ with/without functional constipation & $199 / 566$ & $169 / 596$ & $206 / 559$ & $218 / 547$ & $210 / 555$ & \\
\hline Multivariate adjusted OR $(95 \% \text { CI })^{\mathrm{d}}$ & 1.00 & $0.80(0.63-1.02)$ & $1.03(0.82-1.30)$ & $1.10(0.87-1.38)$ & $1.04(0.83-1.31)$ & 0.15 \\
\hline $\operatorname{Confectioneries}^{\mathrm{e}}(\mathrm{g} / 1,000 \mathrm{kcal})^{\mathrm{c}}$ & $18[1-24]$ & 29 [24-33] & $37[33-42]$ & $47[42-54]$ & $63[54-142]$ & \\
\hline$n$ with/without functional constipation & $162 / 603$ & $185 / 580$ & $191 / 574$ & $224 / 541$ & $240 / 525$ & \\
\hline Multivariate adjusted OR $(95 \% \mathrm{CI})^{\mathrm{d}}$ & 1.00 & $1.17(0.92-1.50)$ & $1.20(0.94-1.53)$ & $1.51(1.19-1.92)$ & $1.64(1.30-2.08)$ & $<0.0001$ \\
\hline Fat and oil $(\mathrm{g} / 1,000 \mathrm{kcal})^{\mathrm{c}}$ & $7[1-8]$ & $10[8-11]$ & 12 [11-14] & 15 [14-18] & 21 [18-67] & \\
\hline$n$ with/without functional constipation & $196 / 569$ & $210 / 555$ & $205 / 560$ & $194 / 571$ & $197 / 568$ & \\
\hline Multivariate adjusted OR $(95 \% \mathrm{CI})^{\mathrm{d}}$ & 1.00 & $1.14(0.91-1.44)$ & $1.11(0.88-1.40)$ & $1.04(0.82-1.32)$ & $1.03(0.81-1.31)$ & 0.90 \\
\hline Pulses $^{\mathrm{f}}(\mathrm{g} / 1,000 \mathrm{kcal})^{\mathrm{c}}$ & $7[0-10]$ & 13 [10-17] & $20[17-25]$ & 30 [25-37] & $48[37-174]$ & \\
\hline$n$ with/without functional constipation & $234 / 531$ & $216 / 549$ & $174 / 591$ & $181 / 584$ & $197 / 568$ & \\
\hline Multivariate adjusted OR $(95 \% \text { CI })^{\mathrm{d}}$ & 1.00 & $0.90(0.72-1.12)$ & $0.64(0.50-0.80)$ & $0.68(0.54-0.86)$ & $0.77(0.61-0.97)$ & 0.003 \\
\hline Fish and shellfish $(\mathrm{g} / 1,000 \mathrm{kcal})^{\mathrm{c}}$ & $11[0-16]$ & 20 [16-24] & $27[24-31]$ & $35[31-41]$ & $50[41-164]$ & \\
\hline$n$ with/without functional constipation & $209 / 556$ & $208 / 557$ & $194 / 571$ & $184 / 581$ & $207 / 558$ & \\
\hline Multivariate adjusted OR $(95 \% \mathrm{CI})^{\mathrm{d}}$ & 1.00 & $1.00(0.80-1.26)$ & $0.92(0.73-1.16)$ & $0.88(0.70-1.11)$ & $0.98(0.78-1.23)$ & 0.54 \\
\hline Meats $(\mathrm{g} / 1,000 \mathrm{kcal})^{\mathrm{c}}$ & $15[0-20]$ & 23 [20-27] & 31 [27-35] & 39 [35-46] & $55[46-134]$ & \\
\hline$n$ with/without functional constipation & $199 / 566$ & $192 / 573$ & $194 / 571$ & $219 / 546$ & $198 / 567$ & \\
\hline Multivariate adjusted OR $(95 \% \text { CI })^{\mathrm{d}}$ & 1.00 & $0.98(0.78-1.24)$ & $1.03(0.81-1.29)$ & $1.17(0.93-1.47)$ & $1.03(0.81-1.30)$ & 0.39 \\
\hline $\operatorname{Eggs}(\mathrm{g} / 1,000 \mathrm{kcal})^{\mathrm{c}}$ & $3[0-5]$ & $8[5-13]$ & 15 [13-20] & 25 [20-29] & $36[29-127]$ & \\
\hline$n$ with/without functional constipation & $192 / 573$ & $211 / 554$ & $197 / 568$ & $200 / 565$ & $202 / 563$ & \\
\hline Multivariate adjusted OR $(95 \% \mathrm{CI})^{\mathrm{d}}$ & 1.00 & $1.12(0.89-1.42)$ & $1.02(0.80-1.29)$ & $1.04(0.82-1.31)$ & $1.12(0.89-1.42)$ & 0.58 \\
\hline Dairy products $(\mathrm{g} / 1,000 \mathrm{kcal})^{\mathrm{c}}$ & $16[0-26]$ & $38[26-52]$ & $66[52-82]$ & $100[82-123]$ & $172[123-596]$ & \\
\hline$n$ with/without functional constipation & $212 / 553$ & $200 / 565$ & $198 / 567$ & $193 / 572$ & $199 / 566$ & \\
\hline Multivariate adjusted OR $(95 \% \mathrm{CI})^{\mathrm{d}}$ & 1.00 & $0.90(0.72-1.14)$ & $0.88(0.70-1.11)$ & $0.87(0.69-1.10)$ & $0.91(0.72-1.15)$ & 0.39 \\
\hline $\operatorname{Vegetables}^{\mathrm{g}}(\mathrm{g} / 1,000 \mathrm{kcal})^{\mathrm{c}}$ & $49[2-67]$ & 80 [67-95] & 110 [95-126] & 146 [126-173] & 221 [173-1142] & \\
\hline$n$ with/without functional constipation & $218 / 547$ & $201 / 564$ & $187 / 578$ & $197 / 568$ & $199 / 566$ & \\
\hline Multivariate adjusted OR $(95 \% \mathrm{CI})^{\mathrm{d}}$ & 1.00 & $0.89(0.71-1.12)$ & $0.81(0.64-1.02)$ & $0.84(0.67-1.06)$ & $0.86(0.68-1.09)$ & 0.18 \\
\hline Fruits $(\mathrm{g} / 1,000 \mathrm{kcal})^{\mathrm{c}}$ & $8[0-14]$ & 20 [14-27] & $36[27-45]$ & $57[45-74]$ & 104 [74-614] & \\
\hline$n$ with/without functional constipation & $224 / 541$ & $189 / 576$ & $201 / 564$ & $176 / 589$ & $212 / 553$ & \\
\hline Multivariate adjusted OR $(95 \% \mathrm{CI})^{\mathrm{d}}$ & 1.00 & $0.80(0.64-1.01)$ & $0.84(0.67-1.06)$ & $0.70(0.55-0.89)$ & $0.87(0.69-1.09)$ & 0.11 \\
\hline Water $(\mathrm{g} / 1,000 \mathrm{kcal})^{\mathrm{c}}$ & $0[0]$ & $11[2-14]$ & $34[14-62]$ & $96[62-185]$ & 319 [185-1649] & \\
\hline functional constipation & $319 / 950$ & $62 / 199$ & $205 / 560$ & $203 / 562$ & $213 / 552$ & \\
\hline Multivariate adjusted OR $(95 \% \mathrm{CI})^{\mathrm{d}}$ & 1.00 & $0.93(0.68-1.28)$ & $1.05(0.85-1.29)$ & $1.04(0.84-1.28)$ & $1.10(0.89-1.35)$ & 0.36 \\
\hline Japanese and Chinese tea $^{\mathrm{h}}(\mathrm{g} / 1,000 \mathrm{kcal})^{\mathrm{c}}$ & $44[0-80]$ & $124[80-189]$ & $237[189-288]$ & $366[288-459]$ & 635 [459-1806] & \\
\hline$n$ with/without functional constipation & $212 / 553$ & $190 / 575$ & $188 / 577$ & $210 / 555$ & $202 / 563$ & \\
\hline Multivariate adjusted OR $(95 \% \text { CI })^{\mathrm{d}}$ & 1.00 & $0.87(0.69-1.09)$ & $0.86(0.68-1.09)$ & $1.00(0.79-1.26)$ & $0.93(0.74-1.17)$ & 0.97 \\
\hline Black tea $^{\mathrm{i}}(\mathrm{g} / 1,000 \mathrm{kcal})^{\mathrm{c}}$ & $0[0]$ & $11[2-14]$ & 25 [14-40] & $72[40-1,069]$ & & \\
\hline$n$ with/without functional constipation & $482 / 1,351$ & $108 / 354$ & $206 / 559$ & $206 / 559$ & & \\
\hline Multivariate adjusted OR $(95 \% \mathrm{CI})^{\mathrm{d}}$ & 1.00 & $1.02(0.83-1.24)$ & $0.83(0.63-1.09)$ & $1.02(0.81-1.28)$ & & 0.99 \\
\hline Coffee $(\mathrm{g} / 1,000 \mathrm{kcal})^{\mathrm{c}}$ & $0[0]$ & 13 [4-29] & $65[29-1,282]$ & & & \\
\hline$n$ with/without functional constipation & $638 / 1,800$ & $171 / 451$ & $193 / 572$ & & & \\
\hline Multivariate adjusted OR $(95 \% \mathrm{CI})^{\mathrm{d}}$ & 1.00 & $1.10(0.91-1.34)$ & $1.11(0.87-1.42)$ & & & 0.41 \\
\hline Other nonalcoholic beverages $(\mathrm{g} / 1,000 \mathrm{kcal})^{\mathrm{c}}$ & $\mathrm{c} O[0-0.002]$ & $4[0.002-10]$ & 18 [10-29] & $42[29-61]$ & 96 [61-860] & \\
\hline$n$ with/without functional constipation & $197 / 568$ & $212 / 553$ & $178 / 587$ & $198 / 567$ & $217 / 548$ & \\
\hline Multivariate adjusted OR $(95 \% \mathrm{CI})^{\mathrm{d}}$ & 1.00 & $1.11(0.88-1.40)$ & $0.87(0.69-1.11)$ & $1.02(0.81-1.29)$ & $1.11(0.88-1.40)$ & 0.60 \\
\hline
\end{tabular}

\footnotetext{
${ }^{a}$ Defined according to the Rome I criteria (14).

${ }^{b}$ Except for water ( 5 categories), black tea ( 4 categories), and coffee ( 3 categories) because of more than one fifth nonconsumers.

${ }^{c}$ Values are median [range].

${ }^{\mathrm{d}}$ Adjusted for body mass index $\left(<18.5,18.5-24.9\right.$, and $\left.\geqq 25 \mathrm{~kg} / \mathrm{m}^{2}\right)$, residential block (Hokkaido and Tohoku; Kanto; Hokuriku and Tokai; Kinki; Chugoku and Shikoku; and Kyushu), size of residential area (city with a population $\geqq 1$ million; city with a population $<1$ million; and town and village), current smoking (yes or no), current alcohol drinking (yes or no), oral medication usage (yes or no), physical activity level (quintiles), and energy intake (quintiles).

${ }^{\mathrm{e}}$ Including sugar and sweeteners.

${ }^{\mathrm{f}}$ Including nuts.

${ }^{\mathrm{g}}$ Including mushrooms and sea vegetables.

${ }^{\mathrm{h}}$ Non- and semifermented tea.

${ }^{\mathrm{i}}$ Fermented tea.
} 
adjusted intakes $(\mathrm{g} / 1,000 \mathrm{kcal})$ of the 18 food groups (as shown in Table 2) were examined. We calculated both crude and multivariate adjusted odds ratios (ORs) and 95\% confidence intervals for functional constipation for each quintile category of dietary variables (except for several drinks because more than one-fifth of subjects were nonconsumers) using logistic regression analysis (20). Multivariate adjusted ORs were calculated by adjusting for BMI, residential block, size of residential area, current smoking, current alcohol drinking (yes or no, because of extremely low alcohol intake: mean $=0.8 \mathrm{~g} / \mathrm{d}$ ), oral medication usage, physical activity level (quintiles), and energy intake (quintiles). As results for the crude and multivariate analyses were similar for all variables analyzed, we presented only those derived from the multivariate models. Trend of association was assessed by a logistic regression model assigning scores to the levels of the independent variable. All statistical analyses were performed using SAS statistical software, version 8.2 (SAS Institute Inc., Cary, NC, USA). All reported $p$ values are 2 -tailed, and a $p$ value of $<0.05$ was considered statistically significant.

\section{RESULTS}

Basic characteristics of the subjects are shown in Table 1. Mean ( \pm standard deviation) age, body height, and body weight was $18.1 \pm 0.3 \mathrm{y}, 157.9 \pm 5.3 \mathrm{~cm}$, and $52.3 \pm 7.7 \mathrm{~kg}$, respectively. A total of 1,002 women $(26.2 \%)$ were classified as having constipation. There were more current smokers, alcohol drinkers, and oral medication users among subjects with constipation. Table 2 shows the association between food intake and constipation. There was a clear dose-response relationship between an increased intake of rice and a decreased prevalence of constipation. In comparison with women in the 1st (lowest) quintile of rice consumption, the multivariate adjusted OR for women in the 2nd, 3rd, 4th, and 5th quintiles were 0.81, 0.73, 0.76, and 0.59 , respectively ( $p$ for trend $<0.0001$ ). Pulse intake was also inversely associated with constipation. Multivariate OR in the 2nd, 3rd, 4 th, and 5 th quintiles compared with the 1st quintile were 0.90, 0.64, 0.68, and 0.77 , respectively ( $p$ for trend $=0.003$ ). In contrast, the prevalence of constipation clearly increased with increasing intake of confectioneries. In comparison with women in the 1st quintile, the multivariate adjusted OR for women in the $2 \mathrm{nd}$, 3rd, 4th, and 5 th quintiles were $1.17,1.20,1.51$, and 1.64 , respectively ( $p$ for trend $<0.0001$ ). A positive relationship was also seen between bread intake and constipation. Multivariate OR in the highest quintile was 1.41 compared with those in the lowest quintile ( $p$ for trend $=0.01$ ). No clear associations were observed between constipation and the intake of other foods examined.

\section{DISCUSSION}

To our knowledge, this study is the first to examine food intake as assessed by a validated assessment method (DHQ in the present study) in relation to func- tional constipation, as defined according to the Rome I criteria. We found that after controlling for a series of potential confounding factors, the consumption of rice and pulses and of confectioneries and bread were negatively and positively associated with functional constipation, respectively, among this group of young women.

The prevalence of Rome I-defined functional constipation in the present group was $26.2 \%$. A similar prevalence by these criteria has been observed in Canadian $(21.0 \%)(4)$ and Spanish (28.6\%) (2) women, whereas a somewhat smaller ratio was seen in elderly Singaporean women (10.5\%) (3).

We found clear dose-response relationships between increased intake of rice with a decreased prevalence of constipation (Table 2). The favorable effect of rice on constipation has been consistently reported in previous studies conducted in Asian countries, where rice is the main staple food $(3,8,9)$. The reason for the association is unknown. Nakaji et al. (9) hypothesized that the effect of rice is due to its dietary fiber, given that rice is the largest source of dietary fiber for Japanese people (27). In contrast, Wong et al. (3) hypothesized that the effect is explained by the increased energy intake because rice is the largest source of energy. These hypotheses could not be investigated further, however, because the authors used a simple diet questionnaire which did not allow the estimation of dietary intake (3, 9). Our previous results (8) do not support these hypotheses because the association between rice and constipation was not dependent on either energy or dietary fiber intake. Additionally, in the present study, the association between rice and constipation was independent of energy intake; mean dietary fiber intake $(11.8 \mathrm{~g} / \mathrm{d})$ was much lower than the Dietary Goal of dietary fiber of the Dietary Reference Intakes for Japanese, 2005 for this age range $(17 \mathrm{~g} / \mathrm{d})(26)$, and the contribution of rice to dietary fiber was only $10 \%$ (the top contributor was vegetables $(37 \%)$ ). These findings suggest that the effect of rice on constipation is unlikely due to its energy or dietary fiber. Relation of dietary fiber to functional constipation in this population is published elsewhere (28). Rice is a staple food in Japan and a major contributor of many nutrients; some constituents of rice may, either alone or combination, exert a preventive effect on constipation. Alternatively, rice intake might merely reflect an overall healthier lifestyle that may not have been accurately captured and controlled in our analysis.

An inverse association between pulse intake and constipation was observed (Table 2). A similar finding has been reported in a study of the US (7). We also found an adverse effect of confectionery intake (Table 2), which is in agreement with our previous study of young Japanese women (8). Additionally, a positive association of bread intake to constipation was found (Table 2), although we are not aware of any previous report of this association. It is unclear why these foods had such effects on constipation. Given the large number of statistical analyses conducted in the present study, our findings regarding these foods may have been due to 
chance alone. Alternatively, their intake may be a marker of other unknown lifestyle factors that were not addressed in the present study.

In contrast to previous studies $(3,7-11)$, we found no association between constipation and the intake of dairy products, meats, fruits, vegetables, eggs, Japanese and Chinese tea, black tea, coffee, and other nonalcoholic beverages (Table 2). These discrepancies may be at least partly explained by the different populations investigated, different dietary assessment methods used, different definitions of constipation, and differences in the number and type of variables used as confounding factors.

Because it is possible that subjects suffering from constipation might change their diet, our findings, particularly those regarding foods significantly associated with the presence or absence of constipation (rice, pulses, confectioneries, and bread), should be interpreted with caution. We cannot deny the possibility that the associations merely reflect dietary behaviors changed after, not before, the development of constipation, although these foods are not generally considered to influence constipation. As mentioned above, however, previous studies have shown similar findings for rice $(3,8,9)$, pulses (7), and confectioneries (8), but not bread.

All self-reported dietary assessment methods are subject to measurement error and selective under- and overestimation of dietary intake (29). To minimize these possibilities, we used a previously validated DHQ (1517). Additionally, the same tendency of associations between food intakes and constipation was observed in a repeated analysis of 2,717 subjects with a 'physiologically plausible' energy intake, namely those possessing a ratio of reported energy intake to estimated basal metabolic rate [standard value of basal metabolic rate for Japanese women aged $18-29 \mathrm{y}(23.6 \mathrm{kcal} / \mathrm{kg}$ of body weight/d) multiplied by body weight of each subjects (kg) (26)] of 1.2 to 2.5 (30) (data not shown). Thus, although the possibility of measurement error and selective under- or overestimation of dietary intake can never be excluded, data inaccuracy is unlikely to have had a major impact on the findings in the present study.

Given that our subjects were selected female dietetic students who may be highly health conscious, our results are likely not extrapolatable to general populations. Additionally, although we attempted to adjust for a wide range of potential confounding variables, we cannot rule out residual confounding due to these or poorly measured variables such as physical activity level, which was assessed by a limited number of nonvalidated questions, or other unknown variables.

In conclusion, after adjustment for a variety of potential confounders, the intake of rice and pulses and that of confectioneries and bread were negatively and positively associated with functional constipation, respectively, among young women. However, owing to the cross-sectional nature of the present study, which precludes any causal inferences, and the lack of biological explanation for these relationships, further observational and experimental studies are required to clarify these relationships.

\section{Member list of the Freshmen in Dietetic Courses Study II Group}

The members of the Freshmen in Dietetic Courses Study II Group (in addition to the authors) are as follows (shown in alphabetical order of the affiliation): Shiro Awata (Beppu University); Tomoko Watanabe and Ayuho Suzuki (Chiba College of Health Science); Tomoko Abe (Doshisha Women's College); Hitomi Hayabuchi (Fukuoka Women's University); Reiko Ueda (Futaba Nutrition College); Noriko Takeda and Tomoko Matsubara (Hiroshima Bunkyo Women's University); Hiroko Ohwada and Kumi Hirayama (Ibaraki Christian University); Chizuko Maruyama (Japan Women's University); Miyuki Makino (Jin-ai Women's College); Shigeru Tanaka and Nobue Nagasawa (Jumonji University); Fumiko Tonozuka and Sanae Osada (Junior College of Kagawa Nutrition University); Kazuhiro Uenishi (Kagawa Nutrition University); Takiko Sagara (Kanazawa Gakuin College); Yusuke Enomoto, Kazuyo Okayama, and Hideo Ooe (Kitasato Junior College of Health and Hygienic Sciences); Kazuko Nakayama and Michi Furuya (Kochi Gakuen College); Noriko Yagi and Kumiko Soeda (Koshien University); Junko Ikeda (Kyoto Bunkyo Junior College); Ikumi Kitagawa (Kyoto Koka Women's University); Keiko Yokoyama and Reiko Nakayama (Kyoto Women's University); Ayako Miura (Kwassui Women’s College); Keiko Baba (Mie Chukyo University Junior College); Yoshiko Sugiyama and Mika Furuki (Minami Kyushu University); Tamami Oyama (Miyagi Gakuin Women's University); Yoshihiko Naito and Makoto Kato (Mukogawa Women's University); Naoko Hirota (Nagano Prefectural College); Tomiko Tsuji and Kaei Washino (Nagoya Bunri University); Takiko Yawata and Chiho Shimamura (Nara Saho College); Nobuko Murayama (Niigata University of Health and Welfare); Reiko Watanabe (Niigata Women's College); Mitsuyo Yamasaki (Nishikyusyu University); Mari Kitamura (Osaka Aoyama College); Tamami Iwamoto (Prefectural University of Hiroshima); Isao Suzuki and Yuki Sugishima (Prefectural University of Kumamoto); Mieko Aoki (Sanyo Gakuen College); Shoko Nishi (Seibo Jogakuin Junior College); Kenji Toyama and Rie Amamoto (Seinan Jo Gakuin University); Nobuko Takahashi and Ruriko Sasaki (Sendai Shirayuri Women's College); Naoko Kakibuchi (Setouchi Junior College); Miyoko Goto (Shokei Gakuin College); Mariko Watanabe and Masako Yokotsuka (Showa Women's University); Michiyo Kimura (Takasaki University of Health and Welfare); Michiko Hara and Nobuko Kiya (Tenshi College); Junko Hirose, Tomiho Fukui, and Katsumi Shibata (The University of Shiga Prefecture); Ryoko Nishiyama (Toita Women's College); Noriyo Tomita (Tokiwa Junior College); Jun Oka and Tomoko Ide (Tokyo Kasei University); Takamoto Uemura and Tadasu Furusho (Tokyo University of Agriculture); Akiko Notsu and Yae Yokoyama (Tottori College); Toyomi Kuwamori (Toyama College); Setsuko Shirono (Ube Frontier College); Toshinao Goda (University of Shizuoka); Kumiko 
Suizu (Yamaguchi Prefectural University); Hiroko Okamoto (Yamanashi Gakuin Junior College).

\section{REFERENCES}

1) Higgins PD, Johanson JF. 2004. Epidemiology of constipation in North America: a systematic review. Am J Gastroenterol 99: 750-759.

2) Garrigues V, Galvez C, Ortiz V, Ponce M, Nos P, Ponce J. 2004. Prevalence of constipation: agreement among several criteria and evaluation of the diagnostic accuracy of qualifying symptoms and self-reported definition in a population-based survey in Spain. Am J Epidemiol 159: $520-526$.

3) Wong ML, Wee S, Pin CH, Gan GL, Ye HC. 1999. Sociodemographic and lifestyle factors associated with constipation in an elderly Asian community. Am J Gastroenterol 94: 1283-1291.

4) Pare P, Ferrazzi S, Thompson WG, Irvine EJ, Rance L. 2001. An epidemiological survey of constipation in Canada: definitions, rates, demographics, and predictors of health care seeking. Am J Gastroenterol 96: 3130-3137.

5) Talley NJ. 2004. Definitions, epidemiology, and impact of chronic constipation. Rev Gastroenterol Disord 4: S3S10.

6) Locke GR 3rd, Pemberton JH, Phillips SF. 2000. AGA technical review on constipation. American Gastroenterological Association. Gastroenterology 119: 17661778.

7) Sandler RS, Jordan MC, Shelton BJ. 1990. Demographic and dietary determinants of constipation in the US population. Am J Public Health 80: 185-189.

8) Murakami K, Okubo H, Sasaki S. 2006. Dietary intake in relation to self-reported constipation among Japanese women aged 18-20 years. Eur J Clin Nutr 60: 650657.

9) Nakaji S, Tokunaga S, Sakamoto J, Todate M, Shimoyama T, Umeda T, Sugawara K. 2002. Relationship between lifestyle factors and defecation in a Japanese population. Eur J Nutr 41: 244-248.

10) Dukas L, Willett WC, Giovannucci EL. 2003. Association between physical activity, fiber intake, and other lifestyle variables and constipation in a study of women. Am J Gastroenterol 98: 1790-1796.

11) Sanjoaquin MA, Appleby PN, Spencer EA, Key TJ. 2004. Nutrition and lifestyle in relation to bowel movement frequency: a cross-sectional study of 20630 men and women in EPIC-Oxford. Public Health Nutr 7: 77-83.

12) Towers AL, Burgio KL, Locher JL, Merkel IS, Safaeian M, Wald A. 1994. Constipation in the elderly: influence of dietary, psychological, and physiological factors. $\mathrm{J} \mathrm{Am}$ Geriatr Soc 42: 701-706.

13) Campbell AJ, Busby WJ, Horwath CC. 1993. Factors associated with constipation in a community based sample of people aged 70 years and over. J Epidemiol Commun Health 47: 23-26.

14) Whitehead WE, Chaussade S, Corazziari E, Kumar D. 1991. Report of an international workshop on management of constipation. Gastroenterol Int 4: 99-113.

15) Sasaki S, Yanagibori R, Amano K. 1998. Self-administered diet history questionnaire developed for health education: a relative validation of the test-version by comparison with 3-day diet record in women. J Epide- miol 8: 203-215.

16) Sasaki S, Yanagibori R, Amano K. 1998. Validity of a self-administered diet history questionnaire for assessment of sodium and potassium: comparison with single 24-hour urinary excretion. Jpn Circ J 62: 431-435.

17) Sasaki S, Ushio F, Amano K, Morihara M, Todoriki T, Uehara Y, Toyooka T. 2000. Serum biomarker-based validation of a self-administered diet history questionnaire for Japanese subjects. J Nutr Sci Vitaminol 46: 285-296.

18) Ministry of Health and Welfare. 1994. The National Nutrition Survey in Japan, 1992. Ministry of Health and Welfare, Tokyo (in Japanese).

19) Science and Technology Agency. 2000. Standard Tables of Food Composition in Japan, 5th revised ed. Printing Bureau of the Ministry of Finance, Tokyo (in Japanese).

20) Altman DG. 1991. Practical Statistics for Medical Research. Chapman and Hall, New York.

21) Thompson WG, Longstreth GF, Drossman DA, Heaton KW, Irvine EJ, Muller-Lissner SA. 1999. Functional bowel disorders and functional abdominal pain. Gut $\mathbf{4 5}$ : II43-II47.

22) Matsuzawa Y, Inoue S, Ikeda Y, Sakata T, Saito Y, Sato Y, Shirai K, Ono M, Miyazaki S, Tokunaga K, Fukagawa K, Yamanouchi K, Nakamura T. 2000. The judgment criteria for new overweight, and the diagnostic standard for obesity. Himan Kenkyu 6: 18-28 (in Japanese).

23) Ministry of Health, Labour, and Welfare. 2004. The National Nutrition Survey in Japan, 2002. Ministry of Health, Labour, and Welfare, Tokyo (in Japanese).

24) Ainsworth BE, Haskell WL, Leon AS, Jacobs DR Jr, Montoye HJ, Sallis JF, Paffenbarger RS Jr. 1993. Compendium of physical activities: classification of energy costs of human physical activities. Med Sci Sports Exerc 25: 71-80.

25) Ainsworth BE, Haskell WL, Whitt MC, Irwin ML, Swartz AM, Strath SJ, O’Brien WL, Bassett DR Jr, Schmitz KH, Emplaincourt PO, Jacobs DR Jr, Leon AS. 2000. Compendium of physical activities: an update of activity codes and MET intensities. Med Sci Sports Exerc 32: S498-S504.

26) Ministry of Health, Labour, and Welfare, Japan. 2005. Dietary Reference Intakes for Japanese, 2005. Daiichi Shuppan Publishing Co., Ltd., Tokyo (in Japanese).

27) Sasaki S, Matsumura Y, Ishihara J, Tsugane S. 2003. Validity of a self-administered food frequency questionnaire used in the 5-year follow-up survey of the JPHC Study Cohort I to assess dietary fiber intake: comparison with dietary records. J Epidemiol 13: S106-S114.

28) Murakami K, Sasaki S, Okubo H, Takahashi Y, Hosoi Y, Itabashi M, the Freshmen in Dietetic Courses Study II Group. 2006. Association between dietary fiber, water and magnesium intake and functional constipation among young Japanese women. Eur J Clin Nutr (advance online publication, December 6, 2006; doi:10.1038/sj.ejcn. 1602573).

29) Livingstone MBE, Black AE. 2003. Markers of the validity of reported energy intake. J Nutr 133: 895S-920S.

30) Black AE, Coward WA, Cole TJ, Prentice AM. 1996. Human energy expenditure in affluent societies: an analysis of 574 doubly-labelled water measurements. Eur J Clin Nutr 50: 72-92. 